\title{
Elaboración da balanza fiscal de Galicia para o período 2011-2013. Unha análise comparativa co Sistema de Contas Públicas Territorializadas
}

\author{
Juan Alberto Turnes Abelenda* / Xavier Vence Deza \\ Universidade de Santiago de Compostela - Facultade de Ciencias Económicas e Empresariais
}

Recibido: 28 de marzo de 2020 / Aceptado: 8 de xuño de 2020

\begin{abstract}
Resumo
O presente traballo leva a cabo a estimación do saldo da balanza fiscal de Galicia para o período 2011-2013, empregando como base de datos para a imputación do gasto o SICOP, e levando a cabo unha comparativa co saldo estimado no Sistema de Contas Públicas Territorializadas. Como principal novidade, e a diferenza doutros traballos publicados ata o momento para Galicia, o saldo da balanza fiscal preséntase seguindo a seguinte lóxica. En primeiro lugar, elabórase a "balanza fiscal básica", onde soamente se ten en conta o gasto territorializado en Galicia e que se materializa en transferencias da Administración central á Comunidade Autónoma, gasto en bens e servizos e en persoal xunto ao investimento real. Posteriormente, indicarase o saldo da "balanza fiscal ampliada", onde se engaden os gastos financeiros e mais en protección social.

Palabras clave

Balanza fiscal / Sistema de Contas Públicas Territorializadas / Imputación ingresos / Imputación gastos.

\section{Elaboration of the Galician Fiscal Balance for the period 2011-2013. A comparative analysis with the System of Territorialised Public Accounts}

\begin{abstract}
In this work, the Galician fiscal balance for the 2011-2013 period is estimated, using the SICOP as the database for allocating expenditure and carrying out a comparison with the results obtained from the System of Territorialised Public Accounts. As the main innovation. and differing from different works published so far for Galicia, the result of the fiscal balance is presented according to the following logic. Firstly, the "basic fiscal balance" is prepared, where only the territorialised expenditure in Galicia is taken into account and which is materialised in transfers from the Central Administration to the Autonomous Community, expenditure on goods and services, personnel and real investment. Subsequently, the result of the "extended fiscal balance" is indicated, where financial and social protection expenditure is added.
\end{abstract}

Keywords

Fiscal balance / System of Territorialised Public Accounts / Income allocation / Expenditure allocation.

JEL Codes: H70, H71, H72.

\section{Introdución}

O estudo sobre as balanzas fiscais é unha área que se atopa perfectamente asentada no campo da investigación. Os primeiros cálculos foron realizados por Trías Fargas (1960), Castells (1979) e Casells e Parellada (1983). Máis recentemente, unha nova xeración de balanzas fiscais deu comezo cos traballos de Castells et al. (2000) ou Barberán e Uriel (2007). Na mesma liña, a Generalitat de Catalunya estimou a súa propia balanza fiscal para o período 2002-20141.

\footnotetext{
* Correspondencia autor: juanalberto.turnes@usc.es

${ }^{1}$ A elaboración da balanza fiscal de Cataluña baséase nunha metodoloxía desenvolvida polos seguintes autores: Núria Bosch, Joan F. Coroa, Joan Carles Costas, Marta Espasa, Guillem López, Eduard Rius, Joan Ramon Rovira, Ramon Tremosa, Xavier Sala-i-Martín, Joaquim Solé Vilanova, Maite Vilalta, Matias Vives e Antoni Zabalza.
} 
As definicións que se poden dar sobre o que é unha balanza fiscal son varias, e están suxeitas ao obxectivo desta. Facendo referencia aos traballos máis actuais, podemos citar o traballo de Barberán e Uriel (2007), onde a balanza fiscal é entendida como un mecanismo que permite medir a redistribución do gasto que leva a cabo o Estado sobre os individuos que viven en diferentes territorios.

A definición dada por Barberán e Uriel (2007) choca en certa medida coa ofrecida por Montasell e Sánchez (2012). Así, estes últimos autores desligan o obxecto dos seus estudos dos efectos da redistribución do gasto sobre o individuo e centran a súa atención no territorio, isto é, cal é a posición que ocupa un territorio dentro da relación que se dá entre ingresos achegados por este á Administración central e os gastos que recibe por parte da dita Administración. En Bosch e Espassa (2014) faise tamén unha clara referencia ao territorio como suxeito principal.

Un dos traballos recentes, e que promoveu unha profunda discusión ao seu redor, é o denominado como Sistema de Contas Públicas Territorializadas (SCPT), cuxa metodoloxía foi elaborada por De la Fuente, Barberán e Uriel (2014). Un dos principais aspectos que cómpre ter en conta deste traballo é que, segundo estes autores, se asume que o resultado proporcionado por unha balanza fiscal é pouco relevante, xa que deriva dunha agregación de partidas de moi distinta natureza e que responden a lóxicas moi diversas. 0 que importa para estes autores, pois, son unhas contas territorializadas que permitan comparar entre territorios o maior número posible de agregados de ingresos e gastos. Por outra banda, é importante sinalar que as contas territoralizadas elaboradas por De la Fuente et al. (2014) teñen como principal obxectivo o estudo da equidade, isto é, a relación existente entre o que os cidadáns pagan e a contraprestación que reciben por parte do Goberno central en forma de bens e servizos. Polo tanto, este traballo, como no caso do de Barberán e Uriel (2007), volve ter como centro de estudo o individuo.

Consonte ás definicións da balanza fiscal e aos fundamentos teóricos que a sustentan, desenvólvense diferentes metodoloxías, sendo principalmente dúas as máis relevantes: a de carga-beneficio e a de fluxo monetario. Os primeiros traballos empregaban o método denominado recadación-pago, onde o principal problema residía en como poder imputar aquel gasto que non estaba estruturado por provincias. A partir do xa mencionado traballo de Castells (1979), a metodoloxía carga-beneficio comeza a expandirse e será a máis empregada nas seguintes análises realizadas.

Ademais, a maioría de autores que realizan as balanzas fiscais desde o punto de vista da Administración central adoitan defender o método de carga-beneficio, xa que como se sinala no traballo de De la Fuente et al. (2014) esta é a única metodoloxía válida para medir a equidade. Desta forma, a outra metodoloxía empregada na elaboración das balanzas fiscais -a denominada fluxo monetario- xa queda desde o inicio totalmente deslexitimada, posto que a través desta fórmula non se pode medir a equidade entre o que pagan os cidadáns e o que reciben do Estado.

0 debate existente sobre cal pode ser a metodoloxía máis idónea para o cálculo dunha balanza fiscal atópase en continua vixencia. Se facemos un percorrido sobre as balanzas fiscais no plano internacional, Bosch e Espasa (2014) sinalan que o método máis empregado para o seu cálculo nos países con maior tradición, como Canadá, Estados Unidos, Australia, Bélxica ou Alemaña, é o de fluxo monetario. Con todo, tamén se sinala que o único informe elaborado pola UE emprega ambas as metodoloxías, e Vaillancourt (2014) argumenta que, entre todas as metodoloxías, a máis idónea para a construción da balanza fiscal é a denominada carga-beneficio. Por outra banda, e tendo en conta os argumentos de Borrell (2015), poderíase sinalar que practicamente non existen balanzas fiscais noutro país que non sexa España, e que os informes que se poden ter en conta doutros países non poden ser considerados como oficiais. Polo tanto, estamos xa ante un primeiro problema que implica un profundo desacordo sobre cal debe ser a metodoloxía idónea.

Outro aspecto clave que envolve a polémica xerada sobre que enfoque empregar refírese á rigorosidade das dúas metodoloxías. Algúns autores, como é o caso de Barberán (2014), manifestan que o método carga-beneficio ofrece unha visión máis ampla sobre os fluxos fiscais que a proporcionada polo método fluxo monetario. Agora ben, considerando os argumentos de Bosch e Espasa (2014), esa maior información implica asumir unha serie de cálculos moi complexos e de supostos que en moitos 
casos carecen dunha clara base científica, debido á falta de instrumentos necesarios para medir determinada información. Poderíanse mencionar, como sinala López i Casasnovas (2014), aqueles supostos que implican asumir o traslado cara adiante ou cara atrás das cotizacións sociais, cara aos prezos ou cara aos beneficios empresariais. Isto é, pódese afirmar que o alcance do enfoque carga-beneficio pretende ser moi ambicioso, agora ben, tal ambición provoca que se asuman determinados postulados que poden chegar a ser cuestionables. Así e todo, obviamente, este problema tamén podería aparecer na metodoloxía de fluxo monetario.

Non obstante, se afondamos máis sobre a polémica que pode haber ao redor da metodoloxía empregada para o cálculo da balanza fiscal, pódese concluír que non existe como tal, xa que o que está de fondo é o obxectivo co cal se constrúe unha balanza fiscal.

Non se pode obviar que o razoamento polo cal a Generalitat de Catalunya elabora a súa balanza fiscal non é o mesmo que o empregado polo Ministerio de Facenda para construír o denominado informe sobre SCPT.

Tendo en conta o anteriormente exposto, o núcleo do debate sobre a metodoloxía existente reside na visión subxectiva sobre o que se entende por territorio e a relación deste cos individuos. Así, para aqueles que defenden a metodoloxía carga-beneficio, o único que existe e prevalece son os individuos, que simplemente viven en diferentes latitudes xeográficas pero onde o territorio non existe como suxeito económico propio, é dicir, non ten ningún tipo de incidencia sobre a xeración de riqueza nin sobre a súa distribución. De por parte, para aqueles que defenden a metodoloxía fluxo monetario, o territorio desempeña un rol fundamental xa que si existe como suxeito económico propio, isto é, si que inflúe na xeración de riqueza e en como é distribuída.

Centrándonos en Galicia, os traballos existentes son escasos e practicamente a totalidade das estimacións realizadas forman parte de traballos levados a cabo para o conxunto do Estado (Táboa 1).

Táboa 1. Resultados para Galicia dos principais informes elaborados sobre as BF (en millóns de euros)

\begin{tabular}{llcc}
\hline & Metodoloxía & Saldo & Saldo/PIB \\
\hline Castells et al. (2000) & Carga gasto & 1.547 & $6,00 \%$ \\
& Carga-beneficio & 1.980 & $7,70 \%$ \\
Barberán e Uriel (2007) & $\begin{array}{l}\text { Carga-beneficio (incluíndo } \\
\text { Seguridade Social) }\end{array}$ & 3.850 & $11,03 \%$ \\
& Carga-beneficio (excluíndo & 2.924 & $8,36 \%$ \\
& Seguridade Social) & & \\
Sánchez Maldonado et al. (2002) & Carga-beneficio & 2.142 & $8,30 \%$ \\
Ministerio de Economía e Facenda (2008) & Carga-beneficio & 3.338 & $7,19 \%$ \\
& Fluxo monetario & 3.822 & $8,23 \%$ \\
Sistema de Contas Públicas Territorializadas (2011) & Carga-beneficio (bruto) & 6.044 & $10,80 \%$ \\
& Carga-beneficio (relativo) & 3.240 & $5,79 \%$ \\
Sistema de Contas Públicas Territorializadas (2012) & Carga-beneficio (bruto) & 6.227 & $11,40 \%$ \\
& Carga-beneficio (relativo) & 3.946 & $7,21 \%$ \\
Sistema de Contas Públicas Territorializadas (2013) & Carga-beneficio (bruto) & 6.653 & $12,33 \%$ \\
& Carga-beneficio (relativo) & 3.701 & $6,86 \%$ \\
Sistema de Contas Públicas Territorializadas (2014) & Carga-beneficio (bruto) & 5.795 & $10,80 \%$ \\
& Carga-beneficio (relativo) & 3.692 & $6,85 \%$ \\
\hline
\end{tabular}

Fonte: elaboración propia. 
Unha das investigacións que podería ser resaltada debido a que recolle unha serie histórica dos saldos das balanzas fiscais para todas as CC.AA. é a elaborada por Barberán e Uriel $(2014)^{2}$, na cal se elaboran as balanzas fiscais para o período 1991-2011 empregando a metodoloxía carga-beneficio. Neste traballo pódese obter o saldo da balanza fiscal de Galicia incorporando o saldo da Seguridade Social ou omitíndoo. Desta forma, o saldo medio que se obtén para Galicia durante o período establecido e coa incorporación do saldo da Seguridade Social é de 2.991 millóns de euros. Se non se ten en conta a Seguridade Social, o saldo medio sería de 2.277 millóns. Así pois, a porcentaxe media da Seguridade Social no resultado da balanza fiscal sitúase no dito período aproximadamente no $28 \%$.

Como se indicou, case ningún traballo de relevancia foi executado exclusivamente desde Galicia, a excepción do elaborado por Caramés (2004). Neste informe, o autor calcula o saldo fiscal para Galicia desde as dúas principais metodoloxías -fluxo monetario e carga-beneficio- para o período 1991-1997 (Táboa 2).

Táboa 2. Resultado BF de Galicia 1991-1997. Carga-beneficio e fluxo monetario (con e sen Seguridade Social) (en millóns de euros)

\begin{tabular}{lccccccc}
\hline & 1991 & 1992 & 1993 & 1994 & 1995 & 1996 & 1997 \\
\hline Fluxo monetario sen SS & -909 & -492 & -95 & -571 & -153 & -823 & -993 \\
Fluxo monetario con SS & 1.013 & 1.802 & 2.250 & 1.750 & 2.408 & 2.455 & 1.700 \\
Fluxo monetario (con SS e neutralizada) & 628 & 1.597 & 1.178 & 1.231 & 1.184 & 2.150 & 1.236 \\
Carga-beneficio sen SS & -597 & -179 & 148 & -386 & 67 & -542 & -787 \\
Carga-beneficio con SS & 1.080 & 2.141 & 2.547 & 1.972 & 2.666 & 2.765 & 1.930 \\
Carga-beneficio (con SS e neutralizada) & 829 & 1.864 & 1.477 & 1.274 & 1.910 & 2.416 & 1.371 \\
\hline
\end{tabular}

Fonte: elaboración propia a partir de Caramés (2004).

Galicia, sen ter en conta a Seguridade Social, mantería un déficit (achegaría máis recursos dos que percibiría) na súa balanza fiscal tanto desde a perspectiva de fluxo monetario como desde a de carga-beneficio, a excepción dos anos 1993 e 1995, cuxos saldos serían, desde a óptica do beneficio, de 148 e de 67 millóns, respectivamente. Así pois, só cando se engade o saldo da Seguridade Social o resultado da balanza fiscal de Galicia varía e pasa a ser superavitaria (recibe máis recursos por parte da Administración central dos que achega).

Asumindo o debate constante que existe ao redor da balanza fiscal, o presente traballo ten como obxectivo fundamental elaborar a balanza fiscal de Galicia para o período 2011-2013 desde a perspectiva fluxo monetario e realizando unha comparativa cos resultados ofrecidos polo Sistema de Contas Públicas Territorializadas. Ademais, tamén se ten como obxectivo establecer unha separación entre dous hipotéticos saldos fiscais, o que supón unha importante novidade metodolóxica: o saldo da balanza fiscal básica e o saldo da balanza fiscal ampliada. Xa que logo, en primeiro lugar trátase de presentar o saldo da balanza fiscal básica, na cal se teñen en conta soamente as transferencias da Administración central a Galicia e o gasto en bens, servizos, persoal e investimento. Posteriormente, estimarase o saldo da balanza fiscal ampliada, onde se engade o gasto financeiro e en protección social.

0 presente traballo estrutúrase da seguinte forma. No apartado 2 desenvólvese a metodoloxía para o cálculo da balanza fiscal e estímanse os ingresos e gastos. No punto 3 calcúlase o saldo fiscal básico e ampliado para Galicia e lévase a cabo unha análise dos resultados. No apartado 4 realízase unha comparativa do saldo fiscal obtido neste traballo co presentado polo Sistema de Contas Públicas Territorializadas. Finalmente, no punto 5 expóñense as principais conclusións.

\footnotetext{
2 Este traballo é unha actualización de Barberán e Uriel (2007).
} 


\section{Elaboración da balanza fiscal de Galicia para o período 2011-2013}

\subsection{Xustificación da metodoloxía desenvolvida}

O método seleccionado para a construción da balanza fiscal de Galicia segue a grandes liñas o de fluxo monetario, aínda que se asumen hipóteses propias e diferentes ás asumidas no fluxo monetario. A razón pola cal é establecida esta metodoloxía baséase nos seguintes puntos.

-O primeiro punto é que un dos obxectivos deste traballo é comparar os resultados acadados a través da metodoloxía fluxo monetario cos proporcionados polo SCPT, que emprega a metodoloxía carga-beneficio.

- Galicia non rexistra, a excepción do traballo sinalado de Caramés (2004) e do presentado polo Ministerio de Economía e Facenda no ano 2008, ningún traballo académico que analice as balanzas fiscais desde a perspectiva do fluxo monetario. Desta forma, Galicia non conta con ningunha información recente que identifique cal é o saldo fiscal da Comunidade desde esta perspectiva.

- Por outra banda, resulta fundamental sinalar que a través deste traballo se procura analizar exclusivamente a contraprestación que recibe un territorio (neste caso Galicia), por parte da Administración xeral, polos recursos que achega aos ingresos totais do Estado. Desta forma, e como non se está medindo a equidade nin tampouco se pretende facer unha comparativa homoxénea entre os diversos territorios de España en termos de agregados orzamentarios moi diversos, a única metodoloxía interesada é, pois, a de fluxo monetario.

Como se indicou no apartado 1, o saldo fiscal de Galicia será presentado a través do saldo fiscal básico e ampliado. Os motivos polos que se realiza esta diferenza fundaméntanse en:

- Poder diferenciar con claridade a natureza do gasto.

- Separar o recibido por Galicia desde o Estado en bens, servizos e investimentos do recibido en forma de rendas individuais (protección social).

- Diferenciar con claridade aquel gasto que se materializa de forma real (bens e servizos e investimento) con aqueloutro que non recibe un territorio de forma material senón que responde a unha determinada lóxica de imputación, como son os gastos financeiros, e que, polo tanto, dependendo das hipóteses empregadas, estes gastos imputados pode variar moi significativamente.

- Poder separar aquel gasto que é financiado a través dos impostos directos e indirectos daqueloutro que se financia a través dun sistema específico, como é o caso da Seguridade Social.

\subsection{Fontes de datos e variables consideradas de ingresos e gastos}

Neste traballo de investigación empregaremos como fonte de datos para os ingresos públicos os orzamentos liquidados do Estado, que son publicados na páxina web da Intervención Xeral da Administración do Estado (IXAE).

Respecto a aquela información que xa é recollida de forma territorializada, como é o caso do IRPF e dos ingresos de explotación das empresas públicas AENA e Portos do Estado, as bases consultadas foron a Axencia Tributaria e as memorias anuais que publican as dúas empresas.

A porcentaxe de imputación sitúase nunha media do $87 \%$ dos ingresos totais do Estado (non se consideran as operacións financeiras). Nos impostos directos e indirectos estamos a excluír todos aqueles que están cedidos na súa totalidade ás Comunidades Autónomas.

No caso das transferencias correntes, estas están formadas polo recibido de: O0.AA., Seguridade Social, axencias estatais, sociedades e entidades públicas estatais, CC.AA., EE.LL., empresas persoais, 
familias, institucións sen fin de lucro e, finalmente, polas transferencias recibidas do exterior. No presente estudo préstaselles atención a aquelas que corresponden coas realizadas polas Comunidades Autónomas á Administración central. Estas transferencias correspóndense coa liquidación que se fai do modelo de financiamento autonómico. Así pois, tales transferencias teranse en conta pola parte da imputación do gasto da Administración central en Galicia cando se calcule o recibido por Galicia correspondente ao financiamento autonómico.

A cuestión máis relevante que resolver á hora de efectuar a imputación territorial dos ingresos é diferenciar entre quen soporta un imposto e quen o paga finalmente. É dicir, en determinados tipos de impostos aqueles axentes sobre os que recae o gravame non son os que finalmente realizan o pago, senón que estes llelo trasladan a outros axentes. Se os que realizan o pago do imposto foran ao mesmo tempo os que o soportaron, efectivamente non habería ningún problema de cálculo; simplemente, obteríase o dato directamente do axente que realizase o pagamento, pero como nunha gran parte dos impostos existe translación da carga, resulta necesario levar a cabo unha serie de cálculos.

- Impostos directos

-IRPF: No presente traballo óptase por imputar a parte estatal da cota resultante da autoliquidación que é proporcionada polas estatísticas da Axencia Tributaria (Táboa 3).

Ademais, resulta preciso destacar que a través desta metodoloxía se recolle parte da progresividade do imposto e certo grao de translación. Por tanto, esta fonte podería ser empregada para a elaboración das balanzas fiscais desde os dous puntos de vista.

- Imposto sobre a Renda dos non Residentes e Imposto sobre Primas de Seguro: Aínda que na metodoloxía carga-beneficio non se realiza a imputación dos ditos impostos, desde o punto de vista do fluxo monetario si son considerados. A imputación é directa (Táboa 3).

-Imposto de Sociedades: Resulta un dos impostos máis polémicos, posto que o seu cálculo produce moitas incertezas. Este imposto en principio podería ser trasladado, é dicir, quen finalmente o pagaría serían os consumidores a través da subida dos prezos. Con todo, realmente non existe ningún estudo que verifique tal posibilidade (Táboa 3 ).

Así pois, son diversas as hipóteses que se realizan co obxectivo de precisar a contía do dito imposto. A primeira delas asume que non existe translación e que por tanto son os accionistas os que teñen que facerlle fronte ao pago. 0 método de imputación, desde este punto de vista, consiste en empregar como indicador o excedente bruto de explotación.

Outra das hipóteses consiste en considerar que existe translación e que son os consumidores, pola vía da suba de prezos, os que cargan con este imposto. 0 criterio de imputación resulta ser o consumo final dos fogares. Por último, e sendo quizais o método máis empregado por autores como Caramés (2004) ou Barberán e Uriel (2007), realízase un reparto dun terzo entre accionistas, consumidores e traballadores.

No caso do grupo de expertos que elaboran as balanzas fiscais de Cataluña, este imposto é imputado a través do excedente bruto de explotación.

No informe sobre o Sistema de Contas Públicas Territorializadas, a metodoloxía desenvolvida por De la Fuente et al. (2014) imputa o Imposto de Sociedades a través da seguinte forma: $1 / 3$ en proporción aos ingresos das rendas societarias acorde coa residencia dos seus perceptores, $1 / 3$ en proporción á remuneración de asalariados e 1/3 en función dun indicador de consumo, en concreto a electricidade.

No presente traballo o devandito imposto será imputado a través do PIB, xa que se considera que a través deste método se abranguen os tres sectores implicados: os accionistas mediante o beneficio empresarial, os empregados a través da retribución dos asalariados e os consumidores en función dos prezos de bens e servizos, todos eles compoñentes do PIB. 
- Impostos indirectos

-IVE: 0 indicador de repartición territorial para o cálculo do sistema de financiamento autonómico é o índice de consumo elaborado polo INE (Táboa 3).

-Impostos Especiais: Para a imputación destes impostos empregamos o mesmo método que no caso do IVE, é dicir, a través do índice de consumo territorial que establece o INE (Táboa 3).

\section{$\rightarrow$ Outros ingresos}

Neste apartado estamos a incluír: imposto sobre tráfico exterior; taxas, prezos públicos e outros ingresos; ingresos patrimoniais; transferencias correntes de Comunidades Autónomas; e transferencias de capital de Comunidades Autónomas (Táboa 3).

A imputación do imposto sobre tráfico exterior, a imputación de taxas, prezos públicos e outros ingresos e mais a imputación de ingresos patrimoniais efectúanse a través do PIB (Táboa 3).

Para imputar as transferencias correntes e de capital, transferencias que recibe o Estado das Comunidades Autónomas, utilízase a porcentaxe de poboación galega sobre a total do Estado (Táboa 3).

\section{- Ingresos Organismos Autónomos}

Soamente se consideran as taxas, prezos públicos e outros ingresos, os ingresos patrimoniais e as transferencias de capital (de sociedades públicas, empresas persoais e familias e institucións sen fin de lucro). Así pois, os ingresos considerados supoñen unha media aproximadamente do $5 \%$ dos ingresos totais dos Organismos Autónomos. A imputación territorial das partidas seleccionadas realízase do mesmo xeito que no caso anterior (Táboa 3 ).

\section{- Ingresos Empresas Públicas}

Un aspecto que hai que considerar é o relativo á forma de financiamento das empresas públicas. Xa que logo, e seguindo a metodoloxía aplicada polo grupo de expertos que elaboran as balanzas fiscais de Cataluña, se estas empresas son financiadas a través do Estado ou da Unión Europea, estase a falar duns investimentos realizados pola Administración pública. Con todo, se o financiamento se realiza, en gran medida, polos ingresos de explotación obtidos (como é o caso de AENA e de Portos do Estado), deberíanse incluír os ingresos que se obteñen nos diferentes territorios nos que operan. Desta forma, no presente traballo están a imputarse os ingresos de explotación de AENA e de Portos do Estado.

Táboa 3. Ingresos achegados por Galicia ao Estado central, 2011-2013 (en miles de euros)

\begin{tabular}{|c|c|c|c|c|c|c|c|c|c|}
\hline & \multicolumn{3}{|c|}{2011} & \multicolumn{3}{|c|}{2012} & \multicolumn{3}{|c|}{2013} \\
\hline & Estado & Galicia & $\%$ & Estado & Galicia & $\%$ & Estado & Galicia & $\%$ \\
\hline IRPF & 35.541 .737 & 1.763 .849 & 4,96 & 28.557 .084 & 1.879 .627 & 6,58 & 39.019 .911 & 1.899 .056 & 4,87 \\
\hline $\begin{array}{l}\text { Rendas non residentes } \\
\text { e primas de seguro }\end{array}$ & 2.073 .943 & 71.314 & 3,44 & 1.755 .613 & 71.215 & 4,06 & 2.739 .926 & 85.079 & 3,11 \\
\hline Imposto Sociedades & 18.439 .977 & 984.638 & 5,34 & 23.005 .355 & 1.212 .483 & 5,27 & 21.730 .155 & 1.135 .710 & 5,23 \\
\hline IVE & 28.177.246 & 1.805 .642 & 6,41 & 19.068 .240 & 1.229 .598 & 6,45 & 27.537.422 & 1.739 .752 & 6,32 \\
\hline Impostos Especiais & 7.396 .281 & 485.268 & 6,56 & 7.015 .293 & 474.096 & 6,76 & 7.094 .085 & 490.377 & 6,91 \\
\hline $\begin{array}{l}\text { Alcol e bebidas } \\
\text { derivadas }\end{array}$ & 324.246 & 19.563 & 6,03 & 312.754 & 19.161 & 6,13 & 300.643 & 17.565 & 5,84 \\
\hline Produtos intermedios & 7.248 & 491 & 6,77 & 7.200 & 498 & 6,91 & 7.427 & 526 & 7,09 \\
\hline Cervexa & 117.149 & 6.404 & 5,47 & 118.838 & 6.769 & 5,7 & 117.429 & 6.397 & 5,45 \\
\hline Tabaco & 3.046 .238 & 170.882 & 5,61 & 2.966 .718 & 171.184 & 5,77 & 2.746 .582 & 165.690 & 6,03 \\
\hline Hidrocarburos & 3.901 .399 & 287.928 & 7,38 & 3.609 .783 & 276.484 & 7,66 & 3.922 .005 & 300.199 & 7,65 \\
\hline
\end{tabular}


Táboa 3 (continuación). Ingresos achegados por Galicia ao Estado central, 2011-2013 (en miles de euros)

\begin{tabular}{|c|c|c|c|c|c|c|c|c|c|}
\hline & \multicolumn{3}{|c|}{2011} & \multicolumn{3}{|c|}{2012} & \multicolumn{3}{|c|}{2013} \\
\hline & Estado & Galicia & $\%$ & Estado & Galicia & $\%$ & Estado & Galicia & $\%$ \\
\hline $\begin{array}{l}\text { Taxas, prezos públicos } \\
\text { e outros ingresos }\end{array}$ & 6.040 .554 & 322.547 & 5,34 & 10.280 .040 & 541.803 & 5,27 & 9.166 .668 & 479.089 & 5,23 \\
\hline Ingresos patrimoniais & 5.909 .918 & 315.571 & 5,34 & 6.291 .286 & 331.578 & 5,27 & 6.141 .493 & 320.981 & 5,23 \\
\hline Transf. corr. AA.PP. & 0 & 0 & 0 & 0 & 0 & 0 & 0 & 0 & 0 \\
\hline Transf. de capital & 0 & 0 & 0 & 0 & 0 & 0 & 0 & 0 & 0 \\
\hline Imp. tráfico exterior & 1.548 .947 & 82.709 & 5,34 & 1.449 .931 & 76.418 & 5,27 & 1.324 .123 & 69.204 & 5,23 \\
\hline Ingresos 00.AA. & 1.912 .661 & 103.105 & 5,39 & 1.684 .487 & 88.780 & 5,27 & 1.550 .203 & 81.229 & 5,24 \\
\hline Total Ingresos & 107.041 .264 & 5.934 .643 & 5,54 & 99.107 .329 & 5.905 .599 & 5,96 & 116.303 .986 & 6.300 .477 & 5,42 \\
\hline
\end{tabular}

Fonte: elaboración propia a partir do Ministerio de Facenda.

\subsection{Imputación do gasto do Estado en Galicia para o período 2011-2013 segundo o SICOP}

Polo lado dos gastos imputados a Galicia (Táboa 4) as fontes consultadas foron:

-0 denominado SICOP (Sistema de Información de Contabilidade Pública), o cal se fixo público a través do SCPT.

- Os orzamentos liquidados das entidades locais, recollidos no IGAE.

-Os informes definitivos da liquidación do modelo de financiamento autonómico, que son presentados polo Ministerio de Facenda.

- Memorias da Delegación do Goberno en Galicia.

O enfoque fluxo monetario atribúelle o gasto estatal ao territorio onde se produzan os bens e se proporcionen os servizos. Neste caso, a imputación do gasto que realiza o Estado de forma territorializada non presenta problemas destacados, posto que se fai de forma directa seguindo basicamente $o$ criterio de asignación que realiza o Estado.

Con todo, existe unha parte do gasto que non está territorializada, o que implica adoptar unha serie de hipóteses para a súa imputación.

En cada un dos programas de gasto do SICOP, a parte non distribuída xeograficamente por Comunidades Autónomas pódese atopar dividida en tres grandes códigos: varias comunidades, estranxeiro e non rexionalizable. Os criterios adoptados para cada un destes gastos son os seguintes:

-Código de "varias comunidades" (VC). Inclúe aqueles gastos que se realizan en diferentes provincias e rexións e que son dificilmente territorializados. Esta partida impútase xeograficamente a través da súa porcentaxe de territorialización.

-Código de "estranxeiro". Inclúe todos os fluxos de caixa atribuídos xeograficamente fóra do país (o persoal designado no exterior, transferencias externas, etc.). A aplicación da metodoloxía fluxo monetario non leva ningún diñeiro atribuído a gastos clasificados como "estranxeiro".

-Os gastos clasificados como "non rexionalizables" (NR) recollen os gastos que, pola súa natureza, son moi difíciles de atribuírllos a unha área xeográfica específica.

- Na contabilización do SICOP non se teñen en conta os activos financeiros que son identificados como préstamos a curto e longo prazo nin tampouco aqueles activos financeiros en empresas públicas, xa que estes son contabilizados a través do investimento.

- Con respecto ao recibido polo financiamento autonómico e polo financiamento local, o SICOP tamén nos proporciona de forma directa os fondos recibidos por Galicia correspondentes a tales partidas.

-Verbo do gasto en Defensa, para os anos 2011-2013 non se leva a cabo ningunha hipótese de imputación, xa que o SICOP nos proporciona a cifra exacta de gasto territorializado en Galicia 
- Na partida de investimentos recóllese o total do investimento da Administración Xeral do Estado na Comunidade Autónoma, do investimento en Organismos Autónomos que teñen presenza en Galicia e do investimento en empresas públicas e sociedades mercantís estatais. Os datos son obtidos da Memoria da Delegación do Goberno en Galicia.

Táboa 4. Hipótese de imputación do gasto da Administración central en Galicia

\begin{tabular}{|c|c|}
\hline Servizos públicos básicos & Fluxo monetario \\
\hline Defensa & $\begin{array}{l}0 \text { gasto é contabilizado a través do gasto directamente territoriali- } \\
\text { zado. }\end{array}$ \\
\hline Xustiza & $\begin{array}{l}\text { O gasto é contabilizado a través do gasto directamente territoriali- } \\
\text { zado. } 0 \text { gasto imputado a Galicia de varias comunidades e non re- } \\
\text { xionalizable aplícase a Galicia a través da porcentaxe do gasto en sa- } \\
\text { larios en Galicia sobre o total en España. }\end{array}$ \\
\hline Seguridade Cidadá e Institucións Penais & $\begin{array}{l}\text { Para o programa SEGURIDADE CIDADÁ o gasto é contabilizado a } \\
\text { través do gasto directamente territorializado. A contía que lle co- } \\
\text { rresponde ao código de varias comunidades e non rexionalizado é } \\
\text { imputada a través do peso do gasto territorializado en Galicia e do } \\
\text { número de efectivos de forzas e corpos de seguridade do Estado } \\
\text { existentes en Galicia con respecto ao total do Estado. } \\
\text { Para o programa CENTROS E INSTITUCIÓNS PENAIS, o gasto é con- } \\
\text { tabilizado a través do gasto directamente territorializado. A contía } \\
\text { que lle corresponde ao código de varias comunidades e non rexio- } \\
\text { nalizado é imputada a través do peso do gasto territorializado en } \\
\text { Galicia. } \\
\text { Finalmente, o programa FORZAS E CORPOS EN RESERVA e } \\
\text { FORMACIÓN FORZAS E CORPOS DE SEGURIDADE DO ESTADO é } \\
\text { imputado a través do número de efectivos da Garda Civil en Galicia } \\
\text { con respecto ao total. }\end{array}$ \\
\hline Política exterior & Non se considera. \\
\hline \multicolumn{2}{|l|}{ Produción de bens de carácter público } \\
\hline Sanidade & $\begin{array}{l}\text { Imputación directa. Gastos en diversas CC.AA. e non rexionalizable } \\
\text { segundo porcentaxe gasto territorializado. }\end{array}$ \\
\hline Educación & $\begin{array}{l}\text { Imputación directa. Gastos en diversas CC.AA. e non rexionalizable } \\
\text { segundo \% gasto territorializado. Aínda que o SICOP asigna todo o } \\
\text { gasto da UNED a Madrid, no presente traballo óptase por imputar o } \\
\text { dito gasto a Galicia da seguinte forma: emprégase a porcentaxe do } \\
\text { número de alumnos en Galicia con respecto ao total existente en } \\
\text { España. }\end{array}$ \\
\hline Cultura & $\begin{array}{l}\text { Imputación directa. Gastos en diversas CC.AA. segundo \% gasto te- } \\
\text { rritorializado; o gasto non territorializado é imputado a Madrid. }\end{array}$ \\
\hline \multicolumn{2}{|l|}{ Actuacións de carácter económico } \\
\hline Agricultura, pesca e alimentación & $\begin{array}{l}\text { Imputación directa. Gastos en diversas CC.AA. a Madrid e gasto non } \\
\text { territorializado segundo \% gasto territorializado e VAB agrario e } \\
\text { pesqueiro. }\end{array}$ \\
\hline Industria e enerxía & $\begin{array}{l}\text { Imputación directa. Gastos en diversas CC.AA. a Madrid e gasto non } \\
\text { territorializado segundo \% gasto territorializado e VAB industrial. }\end{array}$ \\
\hline
\end{tabular}


Táboa 4 (continuación). Hipótese de imputación do gasto da Administración central en Galicia

\begin{tabular}{|c|c|}
\hline Actuacións de carácter económico & Fluxo monetario \\
\hline Comercio e turismo & $\begin{array}{l}\text { Para o programa de gasto COORDINACIÓN E PROMOCIÓN DO } \\
\text { TURISMO, o gasto é contabilizado a través do gasto directamente } \\
\text { territorializado. A contía que lle corresponde ao código de varias } \\
\text { comunidades e non rexionalizado é imputada a través do peso } \\
\text { do número de turistas en Galicia con respecto ao total do Estado. } \\
\text { Para o resto de programas o gasto é contabilizado a través do } \\
\text { gasto directamente territorializado. A contía que lle corresponde } \\
\text { ao código de non rexionalizado é imputada a través do peso do } \\
\text { gasto territorializado en Galicia. Varias comunidades impútase } \\
\text { directamente a Madrid. }\end{array}$ \\
\hline Subvencións ao transporte & $\begin{array}{l}\text { Imputación directa. Diversas CC.AA. (subvencións a usuarios de } \\
\text { autoestradas) segundo territorialización e non rexionalizables } \\
\text { segundo \% gasto territorializado. }\end{array}$ \\
\hline Infraestruturas & Imputación directa. \\
\hline $\mathrm{I}+\mathrm{D}+\mathrm{i}$ & $\begin{array}{l}\text { Imputación directa. Diversas CC.AA. e gastos non rexionalizables } \\
\text { segundo porcentaxe gasto territorializado; investigadores I+D } \\
\text { en cada territorio. }\end{array}$ \\
\hline Outras actuacións de carácter económico & $\begin{array}{l}\text { Imputación directa. Diversas CC.AA. e gastos non rexionalizables } \\
\text { segundo \% gasto territorializado e parte a Madrid. }\end{array}$ \\
\hline \multicolumn{2}{|l|}{ Actuacións de carácter xeral } \\
\hline Alta dirección & Imputación directa. \\
\hline Servizos de carácter xeral & $\begin{array}{l}\text { Imputación directa. Gastos non rexionalizables segundo \% gasto } \\
\text { territorializado. }\end{array}$ \\
\hline Administración financeira e tributaria & Imputación directa. \\
\hline Transferencias a outras AA.PP. & Imputación directa. \\
\hline Débeda pública & $\begin{array}{l}\text { A imputación dos gastos financeiros do período 2011-2013 rea- } \\
\text { lízase en función do recibido por Galicia a través dos diferentes } \\
\text { fondos creados polo Estado para o rescate das Administracións } \\
\text { rexionais e en función do gasto territorializado en Galicia para } \\
\text { tales anos. }\end{array}$ \\
\hline \multicolumn{2}{|l|}{ Actuacións de protección e promoción social } \\
\hline Pensións & $\begin{array}{l}\text { Imputación directa. Diversos gastos CC.AA. segundo \% gasto te- } \\
\text { rritorializado. }\end{array}$ \\
\hline Servizos sociais e promoción social & $\begin{array}{l}\text { Imputación directa. Diversos gastos CC.AA. segundo \% gasto te- } \\
\text { rritorializado. }\end{array}$ \\
\hline Fomento da ocupación & $\begin{array}{l}\text { Imputación directa. Diversos gastos CC.AA. e gasto non rexiona- } \\
\text { lizable segundo \% gasto territorializado. }\end{array}$ \\
\hline Acceso á vivenda e fomento da edificación & $\begin{array}{l}\text { Imputación directa. Diversos gastos CC.AA. e gasto non rexiona- } \\
\text { lizable segundo \% gasto territorializado. }\end{array}$ \\
\hline
\end{tabular}

Fonte: elaboración propia. 
A través da metodoloxía fluxo monetario non se teñen en conta determinadas partidas de gasto, xa que se considera que non teñen un impacto directo no territorio ou que tal impacto non resulta posible de estimar (Táboa 5). Por exemplo, obviamente o gasto en asuntos exteriores ten unha determinada incidencia na dinámica política e económica no conxunto do Estado, pero esa incidencia, e especialmente para un só territorio, non pode ser estimada. As relacións financeiras coa UE, como foi exposto, tamén son excluídas, xa que o obxectivo da elaboración da balanza fiscal neste traballo é analizar exclusivamente a relación fiscal e a redistribución de recursos entre Galicia e a Administración central. A débeda pública, seguindo outros traballos, tampouco se considera, xa que esta sería estimada a través dos gastos financeiros.

Táboa 5. Gastos non considerados (en millóns de euros)

\begin{tabular}{lccc}
\hline & 2011 & 2012 & 2013 \\
\hline Casa da Xefatura do Estado & 8.434 & 8.160 & 7.934 \\
Cortes Xerais & 216.420 & 206.629 & 201.413 \\
Tribunal de Contas & 57.674 & 55.040 & 57.406 \\
Tribunal Constitucional & 23.160 & 21.176 & 21.314 \\
Consello de Estado & 8.431 & 7.732 & 8.282 \\
Débeda Pública & 71.824 .479 & 81.599 .654 & 102.964 .454 \\
Goberno Poder Xudicial & 58.570 & 53.395 & 53.501 \\
Asuntos Exteriores & 2.404 .427 & 1.181 .584 & 1.388 .328 \\
Presidencia & 380.995 & 446.296 & 426.418 \\
Relacións Financeiras UE & 11.811 .073 & 11.370 .993 & 11.925 .873 \\
GASTO TOTAL NON RECONECIDO & 86.793 .663 & 94.950 .659 & 117.056 .936 \\
\hline
\end{tabular}

Fonte: elaboración propia a partir de IGAE.

\section{Saldo da balanza fiscal básica e ampliada de Galicia para o período 2011-2013 e análise dos resultados}

Como se pon de manifesto na Táboa 6, o saldo da balanza fiscal básica de Galicia para os anos 2011, 2012 e 2013 representa o 0,80\%, (-)0,36\% e (-)1,78\% do PIB galego respectivamente.

Para o ano 2011 o saldo sería positivo, isto é, Galicia recibe máis recursos por parte da Administración central dos que achega. Mentres, nos anos 2012 e 2013 o saldo sería negativo; xa que logo, Galicia proporcionaría máis recursos dos que recibiría. Deste xeito, o saldo fiscal de Galicia (para a balanza fiscal básica) móvese en niveis bastante equilibrados, cunha evolución con tendencia negativa.

Este resultado sitúase dentro da lóxica económica, posto que os territorios achegarían en función da porcentaxe do seu PIB sobre o total do Estado, e recibirían recursos conforme á porcentaxe da súa poboación sobre a do total do Estado.

Cando incorporamos os gastos financeiros ${ }^{3}$ e o gasto en protección social ${ }^{4}$, obtemos o saldo da balanza fiscal ampliada de Galicia, a cal mostra uns resultados significativamente diferentes con respecto ao saldo da balanza fiscal básica (Táboa 7).

Galicia rexistra un saldo da súa balanza fiscal ampliada positivo, isto é, recibe máis recursos dos que achega. Como media, para o devandito período, o saldo fiscal situaríase nos 3.931,6 millóns de euros, representando o 8,78\% do PIB.

A diferenza de resultados entre a balanza fiscal básica e a ampliada resulta ser moi importante, o que implica a necesidade de analizar a evolución de forma pormenorizada tanto da partida de ingresos como da de gastos.

\footnotetext{
3 Os gastos financeiros foron calculados en Turnes (2018).

${ }^{4}$ Os datos de protección social son os presentados no SCPT.
} 
Táboa 6. Resultados BF básica de Galicia, 2011-2013 (en millóns de euros)

\begin{tabular}{lccc}
\hline Ingresos Estado & 2011 & 2012 & 2013 \\
\hline IRPF & 1.764 & 1.880 & 1.899 \\
Rendas non residentes e primas de seguros & 71 & 71 & 85 \\
Imposto Sociedades & 985 & 1.212 & 1.136 \\
IVE & 1.806 & 1.230 & 1.740 \\
Impostos Especiais & 485 & 474 & 490 \\
Outros & 721 & 950 & 869 \\
Ingresos OO.AA. & 103 & 89 & 81 \\
Ingresos EE.PP. & 124 & 127 & 82 \\
TOTAL & 6.058 & 6.032 & 6.382 \\
& & & \\
Gastos totais en Galicia & 2011 & 2012 & 2013 \\
Financiamento autonómico & 2.279 & 2.015 & 1.635 \\
Financiamento local & 864 & 947 & 997 \\
Gasto territorializado & 1.571 & 1.179 & 1.094 \\
Defensa & 360 & 192 & 168 \\
Investimento real & 972 & 1.271 & 1.070 \\
Investimento EE.PP. & 457 & 233 & 443 \\
TOTAL & 6.503 & 5.836 & 5.408 \\
& & & \\
Saldo & 445 & -196 & -974 \\
\% do saldo fiscal sobre PIB galego & 0,8 & $-0,36$ & $-1,78$ \\
\hline
\end{tabular}

Fonte: elaboración propia.

Táboa 7. Resultados BF básica e ampliada de Galicia, 2011-2013 (en millóns de euros)

\begin{tabular}{cccccccc}
\hline & $\begin{array}{c}\text { Saldo fiscal } \\
\text { básico }\end{array}$ & $\begin{array}{c}\text { Gastos } \\
\text { financeiros }\end{array}$ & $\begin{array}{c}\text { Prestacións por } \\
\text { desemprego }\end{array}$ & $\begin{array}{c}\text { Gasto en } \\
\text { Seguridade e } \\
\text { Protec. Social }\end{array}$ & $\begin{array}{c}\text { Total prest. } \\
\text { desemp. e } \\
\text { gasto en SS }\end{array}$ & $\begin{array}{c}\text { Saldo fiscal } \\
\text { BF ampliada }\end{array}$ & $\begin{array}{c}\text { Saldo final } \\
\text { sobre PIB }\end{array}$ \\
\hline 2011 & 445 & 992,54 & 1.673 & 1.675 & 3.348 & 4.785 & $8,56 \%$ \\
2012 & -196 & $1.165,33$ & 1.741 & 2.388 & 4.129 & 5.098 & $9,40 \%$ \\
2013 & -974 & $1.251,51$ & 1.577 & 2.741 & 4.318 & 4.595 & $8,38 \%$ \\
\hline
\end{tabular}

Fonte: elaboración propia e SCPT.

Para o conxunto do período, e centrándonos na balanza fiscal básica, o empeoramento do saldo fiscal de Galicia débese tanto a unha forte caída dos gastos como a un incremento considerable dos recursos achegados por Galicia ao Estado no ano 2012.

Así, mentres os ingresos achegados por Galicia se incrementan nun 5,3\%, pasando de 6.058 millóns de euros no ano 2011 a 6.382 millóns de euros no ano 2013, os gastos reducíronse nun 12,7\%, pasando de 6.738 millóns de euros no 2011 a 5.882 no ano 2013. Con respecto aos gastos, as dúas partidas que caen son o financiamento autonómico e o gasto territorializado.

Con respecto ao financiamento autonómico o descenso é debido, por unha banda, a unha forte caída dos ingresos públicos, que pasaron de 200.676 millóns de euros no ano 2007 a 168.847 no ano 2013, alcanzando o seu mínimo no ano 2009, cunha recadación de 144.023 millóns de euros. Por outra banda, a caída do financiamento autonómico tamén é debida á compensación de exercicios anteriores.

Desta forma, no ano 2012 xeráronse devolucións por parte das Comunidades Autónomas á Administración central por valor de 22.421 millóns de euros, dos cales Galicia tiña que devolver 1.591 mi- 
llóns. É dicir, existiu un gran desaxuste entre as entregas a conta que a Administración central fixo ás CC.AA. no ano 2010 e a posterior liquidación que se fixo das ditas entregas no ano 2012, debido a unha recadación real moito máis baixa da estimada. Como consecuencia, as CC.AA. tiveron que devolver aquela cantidade recibida demais, o cal foi realizado a través da compensación de exercicios posteriores, como acontecerá no ano 2013.

En referencia ao gasto territorializado, a caída prodúcese practicamente na totalidade dos programas de gasto dos diferentes ministerios, aínda que no ano 2013 algúns programas se recuperan en comparación ao ano 2012. As principais reducións do gasto obsérvanse en Educación e Cultura, que pasa de 219 millóns no ano 2011 a 63 millóns no ano 2013. En Industria o gasto descende de 94,6 millóns no ano 2011 a 24 millóns no ano 2013, e en Defensa, de 360 millóns no ano 2011 a 168 millóns no ano 2013. Esta caída no gasto en Defensa débese ao programa "gastos operativos das forzas armadas", que pasa dun gasto de 192,6 millóns no ano 2011 a 71,6 millóns no ano 2013. Con respecto ao gasto dos 00.PP., estes mantéñense estables.

Outro dos factores que resaltar con respecto ás conclusións obtidas sobre a balanza fiscal de Galicia é o correspondente á porcentaxe das diferentes partidas sobre o saldo final. Así, resulta un aspecto fundamental para ter en conta o feito de que no gasto territorializado a principal partida de gasto sexa a realizada polo Ministerio do Interior, que consegue un gasto medio para os anos 2011, 2012 e 2013 do $27,6 \%$ do gasto total levado a cabo pola Administración central.

0 segundo ministerio cun maior peso sobre o gasto é o de Defensa, cuxa porcentaxe é do 17,24\%. Por tanto, o 45\% do gasto territorializado do Estado en Galicia está relacionado cos corpos e forzas de seguridade.

Finalmente, en terceiro lugar atoparíase o Ministerio de Fomento, sen ter en conta os investimentos, que supón como media o 8,7\% do gasto da Administración. Pola contra, ministerios como o de Emprego ou o de Industria representan unha porcentaxe sobre o gasto total do 1,45\% e do 5,2\% respectivamente.

Cando se incorporan os gastos realizados polos 00.PP., existe unha partida que destaca considerablemente. Esta partida sería a executada polo Servizo Público de Emprego Estatal (SEPE) que no ano 2011 foi de 273 millóns, supoñendo o 71,3\%; no ano 2012, de 149 millóns, o 63,4\% do total; e finalmente para o ano 2013, o gasto foi de 123 millóns, o 49,6\% do gasto.

Con todo, habería outras partidas clave para o desenvolvemento económico que terían un peso sobre o gasto total moi reducido. Este sería o caso do gasto realizado polo CSIC, ou outros centros de investigación como o Instituto Oceanográfico ou o Instituto de Saúde Carlos III. Deste xeito, estas tres institucións levaron a cabo un gasto de 33,1 millóns no ano 2011; 26,8 millóns no ano 2012; e 29,1 millóns no ano 2013, o que representa unha porcentaxe sobre o total dos 00.PP. do 8,7\%, o 11,4\% e o $11,8 \%$ para os anos 2011, 2012 e 2013 respectivamente.

Cando nos centramos na balanza fiscal ampliada de Galicia, o saldo final vén marcado polo volume de transferencias que recibe Galicia en protección social e que se incrementan significativamente neses anos como consecuencia da crise, xa que en dous anos o dito gasto se incrementa en case 1.000 millóns de euros.

\section{Comparativa co SCPT}

Se facemos unha comparativa cos resultados que nos ofrece o SCPT para os anos 2011, 2012 e 2013, esta indícanos que o saldo fiscal bruto (equivalente ao saldo da balanza fiscal ampliada) é de 6.044 millóns, 6.227 millóns e 6.653 millóns respectivamente. Tales cantidades equivalen ao 10,80\% para o ano 2011, ao 11,40\% para o ano 2012 e ao 12,33\% para o ano 2013 do PIB galego (Táboa 8).

En contraposición, o saldo da balanza fiscal ampliada calculado no presente traballo foi de 4.785,25 millóns de euros no ano 2011, supoñendo o 8,56\% do PIB galego; para o ano 2012 ascendeu a 5.098,36 millóns, representando o 9,40\% do noso PIB; e finalmente para o ano 2013 o saldo foi de 4.594,98 millóns, o 8,38\% do PIB de Galicia. 
Estes datos indican unha diferenza media anual de 2.376 millóns de euros, equivalente a unha diferenza no PIB galego do $2,73 \%$.

Táboa 8. Comparación Saldo BF ampliada/Saldo SCPT para Galicia, 2011-2013 (en millóns de euros)

\begin{tabular}{ccccc}
\hline & Saldo BF ampliada & Saldo final SCPT & Diferenza & Diferenza sobre PIB \\
\hline 2011 & 4.785 & 6.044 & 1.259 & $2,24 \%$ \\
2012 & 5.098 & 6.227 & 1.129 & $2 \%$ \\
2013 & 4.595 & 6.653 & 2.058 & $3,95 \%$ \\
\hline
\end{tabular}

Fonte: elaboración propia e SCPT.

Esta diferenza é debida principalmente a tres partidas. A primeira delas sería a que recolle o gasto en: Casa da Xefatura do Estado, Cortes Xerais, Tribunal de Contas, Tribunal Constitucional, Consello de Estado, Consello Xeral do Poder Xudicial, Asuntos Exteriores e Presidencia. A non incorporación de tales gastos supón non imputar a Galicia un volume de gasto aproximado de 157 millóns de euros anuais desde a perspectiva carga-beneficio.

Outra das partidas relevantes é aquela que ten que ver con Defensa. Mentres o SCPT imputa a Galicia este gasto conforme á súa poboación, o que equivale a 498 millóns no ano 2011, 534 millóns no ano 2012 e 478 millóns no ano 2013, no presente traballo impútase un gasto de 360 millóns, 192 millóns e 192 millóns para os anos 2011, 2012 e 2013 respectivamente. Isto equivale a unha diferenza media anual de 266,33 millóns.

Os gastos financeiros imputados supoñen unha diferenza aínda máis significativa. Mentres o SCPT imputa uns gastos financeiros de 5.410,71 millóns para o período 2011-2013, neste traballo a imputación da dita partida é de 3.046,26 millóns de euros, o que supón unha diferenza anual de case 800 millóns de euros.

Finalmente, outra diferenza importante é aquela relativa ás axudas da UE. Mentres o SCPT inclúe tales partidas, na metodoloxía empregada neste traballo non se consideran.

Polo tanto, tendo en conta os resultados finais obtidos, pódese indicar que a redistribución de recursos públicos que leva a cabo a Administración central entre os diferentes territorios é considerablemente menor á indicada a través do SCPT, que emprega a metodoloxía carga-beneficio.

\section{Conclusións}

A metodoloxía empregada no presente traballo permitiunos analizar o saldo da balanza fiscal de Galicia dependendo da natureza do gasto. Deste xeito púxose de manifesto a diferenza entre unha balanza fiscal básica e unha balanza fiscal ampliada.

Cando soamente se teñen en conta os gastos en bens, servizos e persoal, as transferencias da Administración central e mais o investimento, o saldo fiscal de Galicia sitúase en equilibrio con tendencia negativa. Como media para os anos 2011-2013, o saldo básico de Galicia representa o 0,44\% do PIB galego.

Cando se incorpora o gasto financeiro e en protección social, o saldo fiscal de Galicia cambia radicalmente. Así, o saldo fiscal ampliado medio de Galicia para os anos 2011-2013 sitúase nos 3.931,6 millóns de euros, representando o 8,78\% do PIB.

Cando comparamos o saldo fiscal ampliado co saldo fiscal bruto proporcionado polo SCPT para Galicia, obsérvase unha diferenza media anual de 2.376 millóns de euros, equivalente a unha diferenza do $2,73 \%$ do PIB galego, o que pon de manifesto ata que punto varía a redistribución do gasto público que realiza a Administración central dependendo da metodoloxía escollida. 


\section{Bibliografía}

Administración General del Estado en Galicia. (2019). Memoria Delegación del Gobierno en Galicia (varios años). A Coruña.

Barberán, R. (2014). Economía y política de las balanzas fiscales en España. Pamplona: Aranzadi.

Barberán, R., e Uriel, E. (2007). Las balanzas fiscales de las Comunidades Autónomas con la Administración Pública Central (1991-2005). Bilbao: Fundación BBVA.

Borrell, J. (2015). Las cuentas y los cuentos de la independencia. Madrid: Los Libros de la Catarata.

Bosch, N., e Espasa, M. (2014). Las balanzas fiscales; un tema polémico. Balanzas Fiscales. IEB Report, I/2014 (pp. 3-5). Barcelona: Institut d'Economia de Barcelona/Instituto de Estudios Fiscales. Recuperado de: https://www.ief.es/docs/destacados/publicaciones/informesIEB/Report 2014 1.pdf

Caramés, L. (2004). A solidariedade interterritorial en España: unha aproximación á balanza fiscal de Galicia. A Coruña: CIEF, Fundación Caixa Galicia.

Castells, A. (1979). Balança fiscal de Catalunya: incidència fiscal de l'actuació de l'Estat. Revista Económica (Banca Catalá), 54, 1-18.

Castells, A., e Parellada, M. (1983). Els fluxos econòmics de Catalunya amb la resta d'Espanya i la resta del món. La Balança de pagaments de Catalunya, 1975. Barcelona: Institut d'Estudis Catalans.

Castells, A., Barberán, R., Bosch, N., Espasa, M., Rodrigo, F., e Ruiz-Huerta, J. (2000). Las balanzas fiscales de las Comunidades Autónomas (1991-1996). Análisis de los flujos fiscales de las Comunidades Autónomas con la Administración Central. Barcelona: Ariel/Fundació Carles Pi i Sunyer d’Estudis Autonòmics i Locals.

De la Fuente, A. (Coord.), Barberán, R., e Uriel, E. (2014). Informe sobre la dimensión territorial de la actuación de las Administraciones Públicas. Propuesta metodológica. Madrid: Fundación SEPI. Recuperado de: https://www.fundacionsepi.es/investigacion/publicaciones/otrasPublicaciones/Dimensi\%C3\%B3n\%20terri torial\%20Act.\%20AAPP\%20propuesta\%20metodologica.pdf

Generalitat de Catalunya. Departament d'Economia i Coneixement. (2014). Metodologia i càlcul de la balança fiscal de Catalunya amb el sector públic central l'any 2011. Monografies 16/2014. Barcelona: Generalitat de Catalunya. Recuperado de:

http://economia.gencat.cat/web/.content/70 economia catalana/arxius/colleccions/monografies/M 1620 $\underline{14 \text { ca.pdf }}$

Fernández, X., e Lago, S. (2016). Balanzas fiscales vs. cuentas públicas territorializadas: análisis y valoración de las diferencias. Revista de Estudos Rexionais, 105, 225-262. Recuperado de:

https://www.redalyc.org/pdf/755/75546514008.pdf

Intervención General del Estado. (2019). Liquidación del Presupuesto (varios años). Madrid: IGAE. Recuperado de: https://www.igae.pap.hacienda.gob.es/sitios/igae/esES/Contabilidad/ContabilidadPublica/CPE/EjecucionPresupuestaria/Paginas/ialiquidacionestado.aspx

López i Casasnovas, G. (2014). El debate de las balanzas fiscales: diálogo de sordos. Balanzas Fiscales. IEB Report, I/2014 (pp. 10-13). Barcelona: Institut d'Economia de Barcelona/Instituto de Estudios Fiscales. Recuperado de: https://www.ief.es/docs/destacados/publicaciones/informesIEB/Report 2014_1.pdf

Ministerio de Economía y Hacienda. (2008). Las balanzas fiscales de las CC.AA. españolas con las AA. públicas centrales 2005. Madrid: Ministerio de Economía y Hacienda. Recuperado de:

https://www.hacienda.gob.es/Documentacion/Publico/GabineteMinistro/Varios/BalanzasFiscalesCCAA.pdf

Ministerio de Hacienda. (2019). Informes sobre la financiación definitiva de las Comunidades Autónomas (varios años). Madrid: Ministerio de Hacienda. Recuperado de:

https://www.hacienda.gob.es/es-

ES/CDI/Paginas/SistemasFinanciacionDeuda/InformacionCCAAs/Informes\%20financiacion\%20comunidade s\%20autonomas2.aspx

Ministerio de Hacienda. (2019). Sistema de Cuentas Públicas Territorializadas (varios años). Madrid: Ministerio de Hacienda. Recuperado de:

https://www.hacienda.gob.es/es-ES/CDI/Paginas/OtraInformacionEconomica/Sistema-cuentasterritorializadas.aspx

Montasell, G., e Sánchez, E. (2012). Comparació internacional de les balances fiscals de les regions amb o sector públic central: una anàlisi de l'efecte redistributiu. Papers de Treball, N. 1/2012. Barcelona: Generalitat de Catalunya, Departament d'Economia i Coneixement. Recuperado de: http://economia.gencat.cat/web/.content/70 economia catalana/arxius/pt 201201.pdf 
Sánchez Maldonado, J., Asensio, M., Atienza, P., Avellaneda, P., Gómez-Sala, J. S., Guarnido, A., Hierro, L. A., Jaén, M., Molina, A., Patiño, D., e Titos, A. (2002). Balanzas fiscales de las comunidades autónomas con la administración central. 1996. Málaga: Universidad de Málaga, Departamento de Hacienda Pública.

Trías Fargas, R. (1960). La balanza de pagos interior. Madrid: Sociedad de Estudios y Publicaciones.

Turnes, A. (2018). Estudo dos fluxos fiscais directos e indirectos entre Galicia e a Administración Central. Unha análise a través da balanza fiscal básica e ampliada e dos fluxos interterritoriais ocultos. (Tese de doutoramento). Santiago de Compostela: Universidade de Santiago de Compostela.

Uriel, E. (2006). Las balanzas fiscales de las Comunidades Autónomas. Investigaciones Regionales, 8, 31-53. Recuperado de: https://old.aecr.org/images//ImatgesArticles/2007/02\%20URIEL.pdf?.ga=2.210894739.729590324.15245 $\underline{58222-177903108.1524558222}$

Vaillancourt, F. (2014). Flujos fiscales regionales: cuantificación, determinantes y interpretación. Balanzas Fiscales, IEB Report, I/2014 (pp. 14-17). Barcelona: Institut d'Economia de Barcelona/Instituto de Estudios Fiscales. Recuperado de: https://www.ief.es/docs/destacados/publicaciones/informesIEB/Report_2014_1.pdf 